\title{
Repair of long-gap esophageal atresia: gastric conduits may improve outcome-a 20-year single center experience
}

\author{
Catherine J. Hunter · Mikael Petrosyan • \\ Meghan E. Connelly · Henri R. Ford · \\ Nam X. Nguyen
}

Accepted: 12 August 2009/Published online: 26 August 2009

(C) The Author(s) 2009. This article is published with open access at Springerlink.com

\begin{abstract}
Introduction Treatment of long-gap esophageal atresia (LEA) is a major challenge. Options for reconstruction include native esophagus, or replacement with stomach, colon, or small intestine. However, debate continues regarding the optimal conduit for esophageal replacement. Methods Medical records of patients with a diagnosis of esophageal atresia during a 20 -year period were reviewed. Results Twenty-eight cases of LEA were identified. Ten patients underwent primary anastomosis either after serial pouch dilations (9/10) and/or after a lengthening procedure $(2 / 10)$. Nine received colonic interpositions, and the remainder were reconstructed with a gastric tube $(n=3)$, or gastric interposition $(n=2)$. One patient died prior to repair, and two await definitive treatment. Repeat esophageal reconstruction was required in four patients because of conduit ischemia. Two ischemic events occurred in the colonic interposition group, and two in the native esophageal repairs. All patients, except one who relocated, received long-term follow-up (mean 4.2 years: range $0.5-$ 11.5 years).

Conclusions Surgeon's expertise and patient's anatomy should be considered when selecting an appropriate operation for LEA. Although native esophagus is generally preferred, it is associated with a high rate of stricture. Although our study has a limited by numbers, we found that patients with gastric conduits had lower complication rates and no conduit ischemia. We suggest that gastric transposition may be favored as an initial reconstructive option.
\end{abstract}

C. J. Hunter · M. Petrosyan ( () - M. E. Connelly ·

H. R. Ford · N. X. Nguyen

Childrens Hospital Los Angeles, Los Angeles, USA

e-mail: mpetrosyan@chla.usc.edu
Keywords Long-gap atresia $\cdot$ Surgery · Esophageal conduit · Pediatric

\section{Introduction}

Esophageal atresia (EA), with or without associated tracheoesophageal fistula (TEF), is a rare congenital malformation, afflicting approximately 1 in every 3,500 live births [1]. In general, the defect can be repaired by primary anastomosis of the proximal and distal esophagus, with concurrent ligation of any TEF, if present. However, the management and treatment of long-gap EA continues to be a major surgical challenge.

The distance between esophageal ends that constitutes a long-gap EA lacks a strict numerical definition. Authors have reported gap intervals measuring greater than $2 \mathrm{~cm}$, or greater than two or three vertebral bodies as constituting a long-gap EA [2, 3]. A $3.5 \mathrm{~cm}$ "ultra-long" gap has also been described $[4,5]$. This lack of conformity in definition has left us to consider long-gap EA in functional, rather than numerical terms. Thus, long-gap EA can be defined as any distance between the esophageal ends in a newborn that is too wide for the surgeon to perform primary anastomosis of the proximal and distal esophagus. Consequently, the distance that constitutes long-gap EA may vary according to the skill and experience of the surgeon performing the repair. This definition may make it difficult to compare case and outcome reports between centers.

The options for reconstruction have included the use of native esophagus, or replacement with stomach, colon, or small intestine [6]. Despite a wide variety of repair options the survival rate of affected infants is greater than $90 \%$ [7]. In general, it is considered preferable to use native esophagus provided that the surgical anastomosis is free from undue tension. However, often there is insufficient 
esophageal length to perform a primary anastomosis, even after serial pouch dilations, and thus a suitable alternative must be used. The complications associated with esophageal reconstruction are well described; they include stricture formation, anastomotic leaks, pneumonia, sepsis, development of gastroesophageal reflux, and esophageal dysmotility [8-10]. Furthermore, there are currently five case reports that suggest that EA may predispose long-term survivors to the development of esophageal carcinoma [11]. The etiology of this phenomenon is not understood. This article reports our experience with the management of EA and surgical reconstruction over a 20 -year period.

\section{Materials and methods}

After obtaining approval from the Institutional Review Board, we performed a retrospective review of all cases of long-gap EA without TEF treated at our institution over a 20-year period (June 1987-May 2007). Demographics, associated malformations, delivery weight, and gestation were recorded. Long-gap EA was defined based on the radiographic imaging with a feeding tube pushing on the proximal pouch ( $>3$ vertebral bodies between pouch ends). Only cases where these images were available were included. Analysis of perioperative management strategies, including the use of esophageal pouch dilations, was conducted. The timing of initial and subsequent surgeries, as well as the choice of conduits was noted.

Short- and long-term complications were recorded, and long-term follow-up provided information as to the chronicity of symptoms. Statistical analysis with student's $t$ test or Mann-Whitney $U$ test was performed.

\section{Results}

During the 20-year study period, there were 28 cases of isolated (type I) long-gap EA. There were 11 girls and 17 boys. One patient was diagnosed as having EA by prenatal sonography during the third trimester. Nineteen children had associated anomalies including, trisomy 21, DiGeorge syndrome, limb, renal, vertebral, and anal malformations. Two children had coexisting duodenal atresia, and ten children had cardiac anomalies including, tetralogy of Fallot, atrioseptal defect, and ventricular septal defect. The average birth weight was 2,217 g (range 1,495-3,900 g) with an average term of 34.5-week gestation (range 3040.1 weeks). In the majority of cases, the diagnosis was confirmed at birth by inability to pass an orogastric tube. Figure 1 shows a contrast study of an infant with long-gap atresia. All children underwent gastrostomy tube placement within the first $24 \mathrm{~h}$ of life. Of those infants, three had a thoracotomy with exploration for primary repair without definitive repair.

Fifty-four percent (15/28) of our patients underwent esophageal dilation, either by bougienage or with fluoroscopically directed dilation. The decision regarding bougienage was based on surgeon preference. Of those who underwent serial pouch dilation, nine eventually had primary anastomosis of their native esophagus. There were a total of ten primary esophageal repairs in our study. The average age at time of primary repair was DOL 81 and depended upon the growth and well being of the infant. Two patients who had primary esophageal repair underwent lengthening procedures, one Kimura procedure and one myotomy. Both of these infants had received preoperative bougienage. The decision to use a conduit rather than attempt primary repair was made by the surgeon, when the gap was felt not to be amenable to attempted primary repair. The remaining repairs were performed using colonic interposition $(n=9)$, interposition with a gastric tube $(n=3)$, or initial gastric pull-up $(n=2)$. The choice of conduit was based on the surgeon preference. All of the colonic interpositions utilized a left colon graft anastomosed to the distal esophageal stump or stomach. Two patients died before esophageal reconstruction, and two patients are awaiting reconstruction. There was no significant difference between the group that underwent primary esophageal repair and those that required other

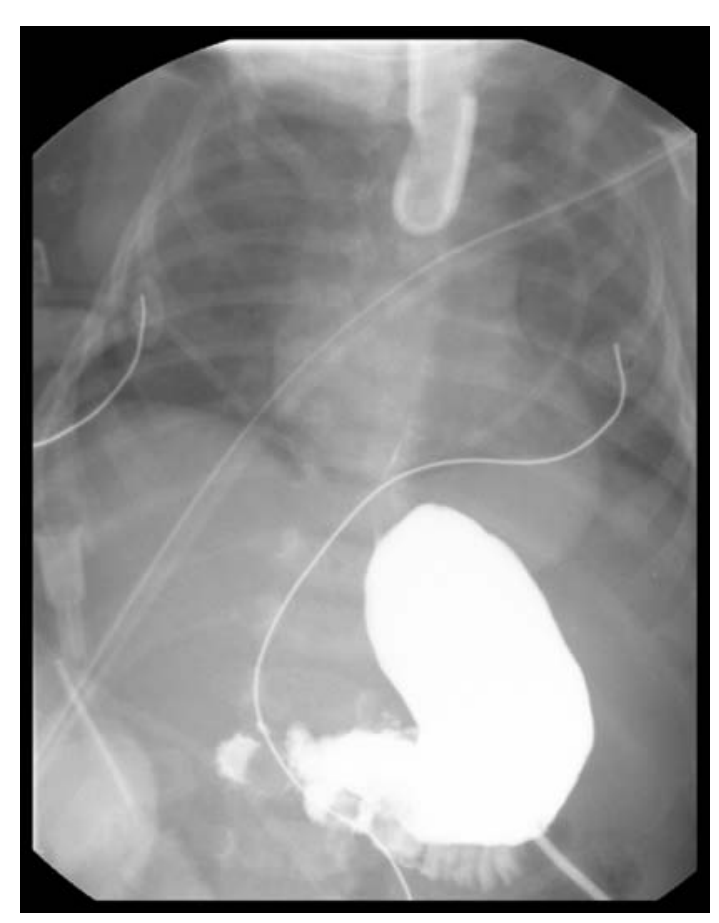

Fig. 1 This is a contrast study demonstrating long-gap esophageal atresia. A dilator is placed within the esophageal pouch and contrast is instilled into the stomach. A distance of 5.5 vertebral bodies is seen between the esophageal remnant and the stomach 
reconstructive methods, with regard to gestational age or birth weight. Although the age at time of repair was slightly greater in those undergoing repair with a conduit (DOL 104 in the conduit group vs. DOL 81 in the primary repair group).

The complications noted for each type of procedure are shown in Table 1. A second esophageal reconstruction was required in four patients because of ischemia and failure of the initial conduit. Two ischemic events occurred in the primary colonic interposition group, and two in the native esophageal repairs (one of which had undergone a Kimura procedure). Ischemic events were defined by reoperation and exploration. Although there was one stricture in the gastric interposition group, complications were less frequent and less morbid in patients who received a gastric conduit compared with the other groups. All patients who underwent gastric pull-up were able to tolerate oral feeds and gain weight appropriately. The patients receiving a gastric tube did not tolerate initial feeds as well as the gastric pull-up group, and gained weight at a slower rate. In contrast, patients who underwent colon interposition were noted to have more frequent gastroesophageal reflux disease and poorer weight gain at long-term follow-up. Patients who underwent primary reconstruction with their native esophagus were frequently troubled with stricture formation (5/10). Sixty percent (3/5) of those who developed strictures required more than 15 surgical dilations. Figure 2 illustrates an intraoperative image of an esophageal stricture in a patient who underwent primary repair with the native esophagus. In addition, $40 \%$ (4/10) of primary repairs with native esophagus were troubled with poor weight gain. All patients, except for one who was transferred to an outside institution received long-term follow-up (mean 4.2 years: range $0.5-11.5$ years). There were three deaths in our study. All deaths occurred prior to reconstruction, one secondary to cardiac arrhythmias, a second due to pulmonary infection, and the third due to refractory GI bleeding at 10 months of age. There were no deaths in those who underwent reconstruction.

\section{Discussion}

The surgical management of patients with long-gap esophageal atresia remains controversial. It has been generally accepted that preservation of the esophagus is the preferred method. Several surgeons have advocated the elongation of the esophagus under traction for use in later construction [5, 12]. Opponents of this technique cite an increased risk of esophageal stricture and esophageal stump tear. Although traction elongation of the esophageal remnant was not used in our study, we did find that $50 \%$ of our patients in whom native esophagus was used for reconstruction developed severe stricture formation requiring multiple dilations. Stricture formation may be related to the degree of anastomotic tension. A tension-free primary esophageal repair is, therefore, considered preferable, but is rarely possible in the long-gap EA. We believe that excessive "tension" may be responsible for the high number of esophageal strictures seen in our series, and the resultant complications. Delayed primary repair typically results in the least amount of motility dysfunction in patients undergoing this procedure when compared with other procedures, but at the expense of a lengthy hospital stay and an increased risk of preoperative aspiration pneumonia [13].

Several authors have suggested the use of myotomies to provide extra length of the native esophagus [14, 15]. In our series and in other reports, it appears that myotomy may have devastating effects on the conduit and may deleteriously affect anastomotic healing [16, 17]. We would, therefore, recommend that myotomy be avoided in favor of other reconstructive options.

As previously mentioned, other methods employed for repair include esophagocoloplasty, small intestine interposition, gastric transposition, and gastric tube interposition [18-21]. Some institutions advocate esophagocoloplasty [22], some prefer gastric transposition [7], and others have described success with the use of a gastric tube [23] as a first-line esophageal replacement therapy. Each of

Table 1 Complications associated with esophageal conduits

\begin{tabular}{|c|c|c|c|c|c|c|c|c|}
\hline Conduit & Stricture & Ischemia & Leak & $\begin{array}{l}\text { Wound } \\
\text { infection }\end{array}$ & Pneumothorax & Pneumonia & $\begin{array}{l}\text { (Severe) } \\
\text { GERD }\end{array}$ & Other \\
\hline Native esophagus & $50 \%(5 / 10)$ & $20 \%(2 / 10)$ & $20 \%(2 / 10)$ & $10 \%(1 / 10)$ & $10 \%(1 / 10)$ & 0 & 0 & $\begin{array}{l}10 \%(1 / 10) \text { tracheal } \\
\text { injury }\end{array}$ \\
\hline Colon & $11 \%(1 / 9)$ & $22 \%(2 / 9)$ & $22 \%(2 / 9)$ & $22 \%(2 / 9)$ & 0 & $11 \%(1 / 9)$ & $22 \%(2 / 9)$ & $\begin{array}{l}11 \%(1 / 9) \text { vocal cord } \\
\text { paralysis } \\
11 \%(1 / 9) \text { late bowel } \\
\text { obstruction }\end{array}$ \\
\hline Gastric tube & $33 \%(1 / 3)$ & 0 & 0 & 0 & $33 \%(1 / 3)$ & 0 & 0 & $\begin{array}{l}33 \%(1 / 3) \text { GI bleed } \\
\text { at staple line }\end{array}$ \\
\hline Gastric interposition & $50 \%(1 / 2)$ & 0 & 0 & 0 & 0 & 0 & 0 & \\
\hline
\end{tabular}




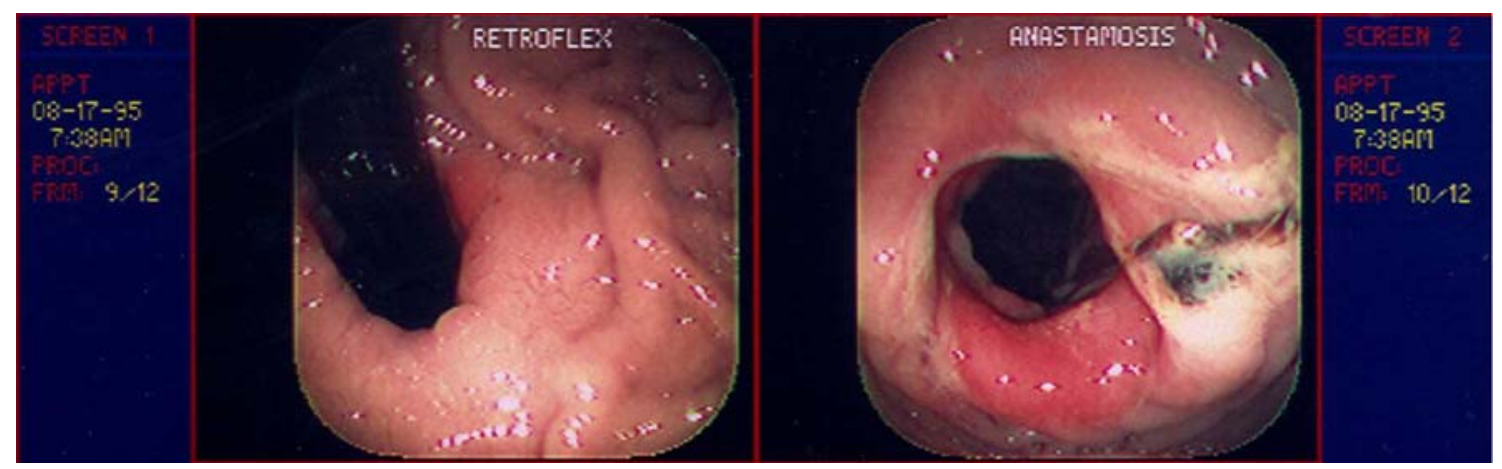

Fig. 2 Intraoperative pictures show an area of esophageal stricture at the level of the anastomosis. After successful balloon dilation, this child had improved ability to tolerate oral feedings and subsequently had improved weight gain

these methods of repair or replacement has its associated limitations and potential complications that may restrict its suitability for a particular patient. Esophageal replacement techniques that use alternative conduits have a number of associated complications, including anastomotic leak, stricture, reflux, diarrhea, abdominal evisceration, interposition redundancy, and hold the possibility of severe complications such as graft necrosis, dehiscence of the colocolic anastomosis, dehiscence of gastrostomy, axial torsion of the stomach, and delayed gastric emptying [2426].

Recently, gastric tube reconstruction was compared with gastric transposition as a conduit for esophageal replacement in children [27]. Although this study did not focus solely on long-gap EA, it demonstrated that gastric transposition was preferable to gastric tube formation, which correlates with our findings in long-gap EA. Another study found that the use of gastric transposition in children was safe, and had fewer complications when compared with adults requiring reconstruction [28]. Given our findings and review of the literature, we also find that gastric transposition is preferable to gastric tube formation.

Unfortunately, in addition to the array of complications that accompany various long-gap EA repair techniques; there is no standard protocol to help guide the surgeon's decision in managing the patient. In our series, we noted the lowest rate of complications and morbidity in those individuals who underwent a gastric transposition. Furthermore, it is possible to perform gastric interposition in a shorter time frame than is required for native esophageal reconstruction. We acknowledge that our study numbers are limited and that we cannot make firm conclusions regarding the choice of repair. However, based on our institutional experience, we feel that gastric interposition may be the preferred initial method of reconstruction in long-gap EA for patients in whom primary repair with native esophagus is not technically feasible without an excessive amount of tension at the anastomosis.

\section{Conclusions}

Treatment of LEA remains a major challenge in pediatric surgery. Although a diverse array of surgical approaches is utilized in the management of this anomaly, controversy exists regarding the optimal strategy. Surgeon's expertise and the patient's anatomy should be considered when selecting an appropriate option. The use of native esophagus is generally preferred; however in our study, it is associated with a high rate of stricture. Although this study is limited by numbers, outcomes with gastric interposition are promising. Because patients with gastric conduits had a lower complication rate and did not experience conduit ischemia, we suggest that gastric transposition may be favored as an initial reconstructive option.

Open Access This article is distributed under the terms of the Creative Commons Attribution Noncommercial License which permits any noncommercial use, distribution, and reproduction in any medium, provided the original author(s) and source are credited.

\section{References}

1. Fraser C, Baird PA (1987) A comparison of incidence trends for esophageal atresia and tracheoesophageal fistula, and infectious disease. Teratology 36:363-369. doi:10.1002/tera.1420360313

2. Hollands CM, Lankau CA Jr (2000) Preoperative home care for esophageal atresia: a survey. J Pediatr Surg 35:279-281. doi: 10.1016/S0022-3468(00)90025-3 (discussion 282)

3. Bagolan P, Iacobelli Bd B, De Angelis P et al (2004) Long gap esophageal atresia and esophageal replacement: moving toward a separation? J Pediatr Surg 39:1084-1090. doi:10.1016/j.jpedsurg. 2004.03.048

4. Foker JE, Linden BC, Boyle EM et al (1997) Development of a true primary repair for the full spectrum of esophageal atresia. 
Ann Surg 226:533-541. doi:10.1097/00000658-19971000000014 discussion 541-533

5. Boyle EM Jr, Irwin ED (1994) Primary repair of ultra-long-gap esophageal atresia: results without a lengthening procedure. Ann Thorac Surg 57:576-579

6. Seguier-Lipszyc E, Bonnard A, Aizenfisz S et al (2005) The management of long gap esophageal atresia. J Pediatr Surg 40:1542-1546. doi:10.1016/j.jpedsurg.2005.06.007

7. Ludman L, Spitz L (2003) Quality of life after gastric transposition for oesophageal atresia. J Pediatr Surg 38:53-57. doi: 10.1053/jpsu.2003.50009 discussion 53-57

8. Ure BM, Slany E, Eypasch EP et al (1995) Long-term functional results and quality of life after colon interposition for long-gap oesophageal atresia. Eur J Pediatr Surg 5:206-210. doi: 10.1055/s-2008-1066206

9. Cimador M, Carta M, Di Pace MR et al (2006) Primary repair in esophageal atresia: the results of long term follow-up. Minerva Pediatr 58:9-13

10. Al-Salem AH, Tayeb M, Khogair S et al (2006) Esophageal atresia with or without tracheoesophageal fistula: success and failure in 94 cases. Ann Saudi Med 26:116-119

11. Pultrum BB, Bijleveld CM, de Langen ZJ et al (2005) Development of an adenocarcinoma of the esophagus 22 years after primary repair of a congenital atresia. J Pediatr Surg 40:e1-e4. doi:10.1016/j.jpedsurg.2005.08.042

12. Paya K, Schlaff N (2007) Isolated ultra-long gap esophageal atresia: successful use of the foker technique. Eur J Pediatr Surg 17:278-281. doi:10.1055/s-2007-965508

13. Varjavandi V, Shi E (2000) Early primary repair of long gap esophageal atresia: the VATER operation. J Pediatr Surg 35:1830-1832. doi:10.1053/jpsu.2000.19279

14. Livaditis A, Radberg L (1972) Esophageal end-to-end anastomosis: reduction of anastomotic tension by circular myotomy. Scand J Thorac Cardiovasc Surg 6:206-214

15. Slim MS (1977) Circular myotomy of the esophagus: clinical application in esophageal atresia. Ann Thorac Surg 23:62-66

16. Tannuri U, Teodoro WR, de Santana Witzel S et al (2003) Livaditis' circular myotomy does not decrease anastomotic leak rates and induces deleterious changes in anastomotic healing. Eur J Pediatr Surg 13:224-230. doi:10.1055/s-2003-42238
17. Tannuri U, Tannuri AC, Fukutaki MF et al (1999) Effects of circular myotomy on the healing of esophageal suture anastomosis: an experimental study. Rev Hosp Clin Fac Med Sao Paulo 54:9-16. doi:10.1590/S0041-87811999000100003

18. Spitz L, Kiely E (1987) Gastric transposition for esophageal replacement in children. Ann Surg 206:69-73. doi: 10.1097/00000658-198707000-00011

19. Tannuri U, Maksoud Filho JG (1994) Esophagocoloplasty in children: surgical technique, with emphasis on the double blood supply to the interposed colon, and results. J Pediatr Surg 29:1434-1438. doi:10.1016/0022-3468(94)90138-4

20. Ring WS, Varco RL, L'Heureux PR et al (1982) Esophageal replacement with jejunum in children: an 18 to 33 year followup. J Thorac Cardiovasc Surg 83:918-927

21. Ruangtrakool R, Spitz L (2000) Early complications of gastric transposition operation. J Med Assoc Thai 83:352-357

22. Tannuri U, Maksoud-Filho JG, Tannuri AC et al (2007) Which is better for esophageal substitution in children, esophagocoloplasty or gastric transposition? A 27-year experience of a single center. J Pediatr Surg 42:500-504. doi:10.1016/j.jpedsurg.2006.10.042

23. Anderson KD, Noblett H, Belsey R et al (1992) Long-term follow-up of children with colon and gastric tube interposition for esophageal atresia. Surgery 111:131-136

24. Shokrollahi K, Barham P, Blazeby JM et al (2002) Surgical revision of dysfunctional colonic interposition after esophagoplasty. Ann Thorac Surg 74:1708-1711. doi: 10.1016/S0003-4975(02)03864-X

25. Chittmittrapap S, Spitz L, Kiely EM et al (1992) Anastomotic leakage following surgery for esophageal atresia. J Pediatr Surg 27:29-32. doi:10.1016/0022-3468(92)90098-R

26. Spitz L (2006) Esophageal atresia: lessons I have learned in a 40year experience. J Pediatr Surg 41:1635-1640. doi: 10.1016/j.jpedsurg.2006.07.004

27. Tannuri U, Tannuri AC, Goncalves ME et al (2008) Total gastric transposition is better than partial gastric tube esophagoplasty for esophageal replacement in children. Dis Esophagus 21:73-77. doi:10.1111/j.1442-2050.2008.00860.x

28. Macksood DJ, Blane CE, Drongowski RA et al (1997) Complications after gastric transposition in children. Can Assoc Radiol J 48:259-264 